\title{
The unilateral adrenal tumor in a patient with history of uterine cervix cancer: the radiological and endocrine profile related management
}

\author{
Mara Carsote ${ }^{1,2}$, Ana Valea ${ }^{3,4}$, Anda Dumitrascu², Dana Terzea 2, 5, Sorin Paun ${ }^{1,6}$, Diana Paun ${ }^{1,2}$, \\ Catalina Poiana ${ }^{1,2}$
}

1. Carol Davila University of Medicine and Pharmacy, Bucharest, Romania. 2. C.I.Parhon National Institute of Endocrinology, Bucharest, Romania. 3. Iuliu Hatieganu University of Medicine and Pharmacy, Cluj-Napoca, Romania. 4. Clinical County Hospital, Cluj-Napoca, Romania. 5. Oncoteam Monza Hospital, Bucharest, Romania. 6. Floreasca Emergency Hospital, Bucharest, Romania

Correspondence: Mara Carsote. Address: Aviatorilor Ave 34-38, sector 1, Bucharest, Romania. Email:

carsote_m@hotmail.com

Received: June 1, 2015

DOI : $10.5430 /$ ijdi.v2n2p90
Accepted: July 7, 2015

Online Published: July 20, 2015

\section{Abstract}

The adrenal tumours represent a large area of pathological diagnosis. The radiological and endocrine features are the best tools in patients' management. The medical history of a cancer increases the metastasis suspicion. We present a 64-year-old hypertensive female with a previous diagnosis (20 years ago) of uterine cervix cancer that was remitted after surgery and local cobalt therapy. Four years before she was found with a non-secretor right adrenal tumor of $2 \mathrm{~cm}$ during a routine ultrasound for a kidney stone crisis. Currently she is admitted for an endocrine control: a mildly increased serum chromogranin A and neuron specific enolase with basal plasma metanephrines 4 times above the upper normal limit and normal plasma normetanephrines are found. The morning plasma cortisol after 2 days of dexamethasone 2 milligrams is 2.3 micrograms/decilitre. The contrast computed tomography of the pelvis, abdomen and thorax found no anomalies but the right adrenal mass with enlarged diameters of $2.55 \mathrm{~cm} \times 4 \mathrm{~cm} \times 4.54 \mathrm{~cm}$. Laparoscopic right adrenalectomy was performed without adrenal insufficiency after surgery, neither remarkable changes in arterial blood pressure profile. The pathological report confirmed an adrenocortical adenoma. The macroscopic aspects showed a yellow tumor of $4 \mathrm{~cm}$. The immunohistochemistry revealed weak positive reaction of melan A+, INHIBIN and SYN (in some tumor areas), negative CROMO (into the tumor cells and positive in normal adrenal medulla), with an index of proliferation (Ki67) of 2\%. 6 months after surgery the patient was clinically stationary and endocrine follow-up is recommended. The radiologic and endocrine anomalies related to an adrenal mass in a patient with oncologic medical history may conclude to the idea of tumor removal for a certain diagnosis provided by pathological exam.

\section{Keywords}

Adrenal tumour, Adrenal incidentaloma, Chromogranin A, Neuron specific enolase 


\section{I ntroduction}

The adrenal masses usually underline a benign diagnosis with either a secretor or a non-secretor endocrine profile. The surgery is performed in every case with clear hyper-functioning features but in endocrine silent neoplasia (or incidentaloma) the decision is strongly related to radiological features: increased diameters at baseline or significant changes during periodic check up. An oncologic context in some patients may raise the question of adrenal metastases ${ }^{[1-3]}$. After surgery the pathological and immunohistochemistry report will point out the precise diagnosis and potential future risks ${ }^{[1]}$. Less than $5 \%$ of the non-functional adrenal tumors associate a malignant behavior and although a general good prognosis is seen the decision should be taken individual ${ }^{[2]}$. The larger the diameters the higher risk of malignancy is found. A good collaborative team between different medical and surgical teams is necessary at first admission of each patient and also during the long term follow-up.

\section{Case presentation}

A 64-year-old female has a 5-year history of high blood pressure and menopausal osteoporosis with adequate therapy. At age of 43 she was diagnosed with uterine cervix cancer that was remitted after total hysterectomy and bilateral adnexectomy associated with local cobalt therapy. She was under oncologic follow-up for more than 10 years without any events. At age of 60 she had an intense lumbar pain caused by a kidney stone which was spontaneously eliminated. The abdominal ultrasound performed at that time found a right adrenal tumor of $2 \mathrm{~cm}$ maximum diameter. The adrenal tests were normal at that moment.

On admission the clinical and endocrine exam is normal as well as routine biochemistry profile. The endocrine parameters reveal a mildly increased level of serum chromogranin A and neuron specific enolase (see Table 1). Basal plasma metanephrines are 4 times above the upper normal limit with normal plasma normetanephrines but when we repeated them the second day a normal value of $73 \mathrm{pg} / \mathrm{ml}$ is found (see Table 1). The morning plasma cortisol after 2 days of dexamethasone $2 \mathrm{mg}$ is suppressed but above the recommended levels of 1.8 micrograms/deciliter $(2.31 \mu \mathrm{g} / \mathrm{dl}){ }^{[4]}$.

Table 1. The endocrine parameters in a 64-year-old female with right adrenal tumour

\begin{tabular}{llll}
\hline Parameter & Level & Normal ranges & Units \\
\hline Serum chromogranin A & 132 & $40-100$ & nanogram/millilitre (ng/ml) \\
Androstenedione & 1.51 & $0.45-4.2$ & $\mathrm{ng} / \mathrm{ml}$ \\
Plasma aldosterone & 71 & $60-160$ & Picograms/millilitre (pg/ml) \\
Basal morning cortisol & 20.55 & $6.2-19.4$ & $\mathrm{microgram} / \mathrm{decilitre} \mathrm{( \mu g/d)}$ \\
Morning plasma ACTH (adrenocorticotrophic hormone) & 13.47 & $3-66$ & $\mathrm{pg} / \mathrm{ml}$ \\
Neuronal specific enolase & 13.7 & $0-12$ & $\mathrm{ng} / \mathrm{ml}$ \\
Plasma metanephrines & 415 & $10-90$ & $\mathrm{pg} / \mathrm{ml}$ \\
\hline Plasma normetaneprines & 110 & $15-180$ & $\mathrm{mIU} / \mathrm{ml}$ \\
\hline Beta-HCG (human chorionic gonadotropin) & 2.06 & $0.5-2.67$ & \\
\hline
\end{tabular}


The contrast computed tomography of the pelvis, abdomen and thorax found a right adrenal mass of $2.55 \mathrm{~cm} \times 4 \mathrm{~cm} \times 4.54$ $\mathrm{cm}$ (oval form, moderate intake of the contrast except of some area with intense uptake, heterogeneous structure) (see Figure 1).
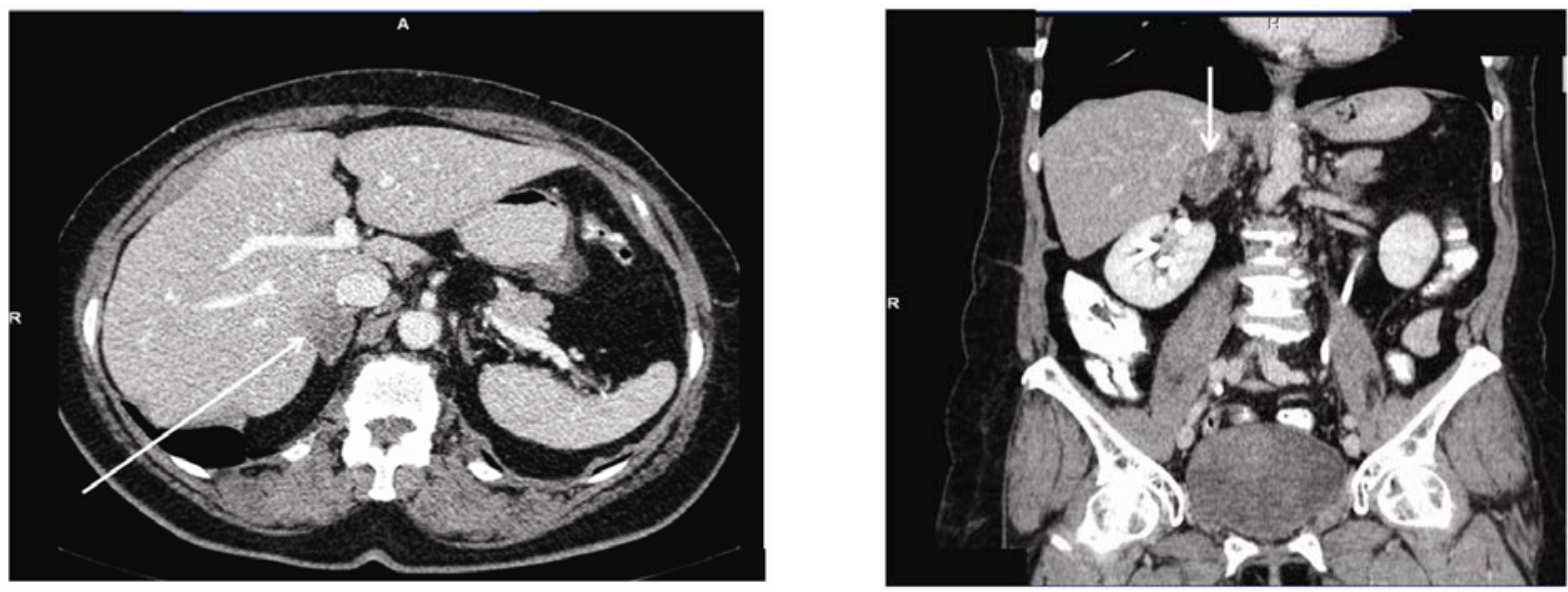

Figure 1. Computed tomography (contrast): right adrenal tumour of $2.55 \mathrm{~cm} \times 4 \mathrm{~cm} \times 4.54 \mathrm{~cm}$ (white arrow). A: transverse plane; B: coronal plane

Based on increased dimensions (higher than recorded in the patient's medical history) and discrete endocrine anomalies the laparoscopic right adrenalectomy was performed without adrenal insufficiency after surgery, neither remarkable changes in arterial blood pressure values and required medication as seen before surgery. The pathological report confirmed an adrenocortical adenoma and normal adrenal medulla; most of cells were round or oval, with eosinophile cytoplasm of granular aspect (see Figure 2).
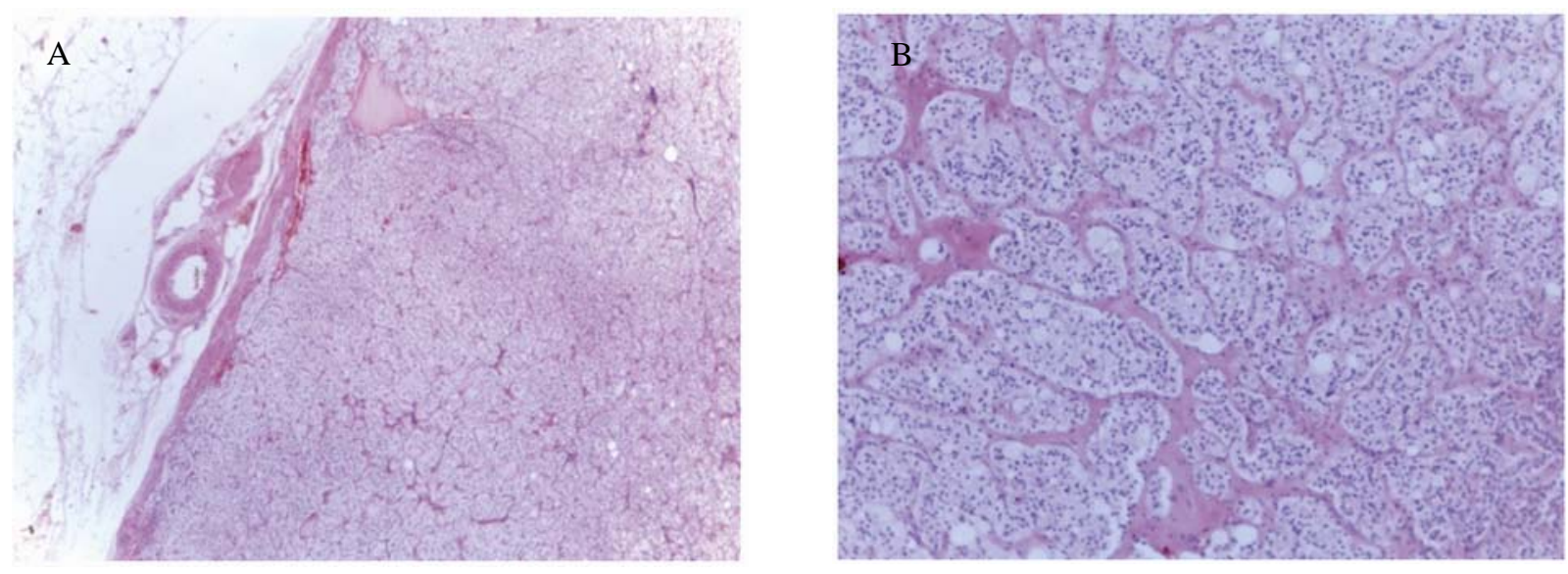

Figure 2. The pathological report in a unilateral adrenocortical adenoma (hematoxiline-eosin). A: Hematoxilin-eosin (4×); B: Hematoxilin-eosin $(10 \times)$

The macroscopic aspects showed a yellow tumour of $4 \mathrm{~cm}$. The immunohistochemistry revealed weak positive reaction of melan A+, INHIBIN and SYN (in some tumour areas), negative CROMO (into the tumour cells and positive in normal adrenal medulla), and a Ki67 of 2\%. Immunohistochemistry report in a unilateral adrenocortical adenoma (see Figure 3).

Six months after surgery the patient is clinically stationary with a normal hormonal profile (see Table 2). The patient is referred to be followed-up by an endocrinologist from her native city. 

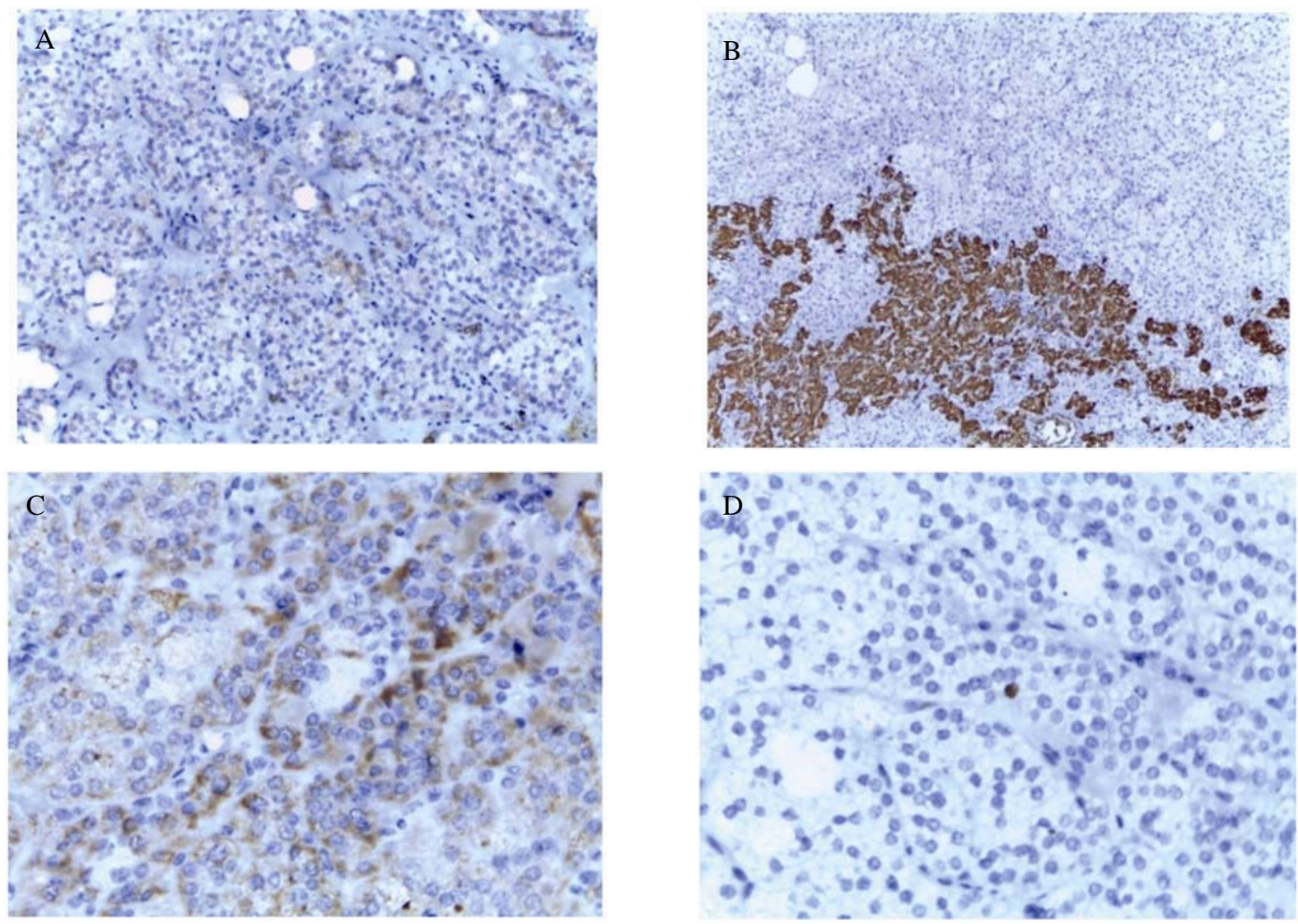

Figure 3. A. Weak positive reaction of INHIBIN in tumour cells (20×); B: Negative CROMO in tumour cells and positive in adrenal medulla (10×); C: Positive MELAN A in tumour cells (40×); D: Positive Ki67 of $2 \%$ in tumour cells (40×)

Table 2. The endocrine parameters in a 64-year-old female 6 months after right adrenalectomy

\begin{tabular}{|c|c|c|c|}
\hline Parameter & Level & Normal ranges & Units \\
\hline Serum chromogranin A & 70.2 & $40-100$ & $\mathrm{ng} / \mathrm{ml}$ \\
\hline Basal morning cortisol & 13.55 & $6.2-19.4$ & $\mu \mathrm{g} / \mathrm{dl}$ \\
\hline $\begin{array}{l}\text { Morning plasma ACTH } \\
\text { (adrenocorticotrophic hormone) }\end{array}$ & 19.47 & 3-66 & $\mathrm{pg} / \mathrm{ml}$ \\
\hline Neuronal specific enolase & 7.9 & $0-12$ & $\mathrm{ng} / \mathrm{ml}$ \\
\hline Plasma metanephrines & 25.1 & $10-90$ & $\mathrm{pg} / \mathrm{ml}$ \\
\hline Plasma normetaneprines & 61.7 & $15-180$ & $\mathrm{pg} / \mathrm{ml}$ \\
\hline
\end{tabular}

\section{Discussion}

This case is related to some interesting topics in adrenal tumours. First aspect is the newly diagnosed adrenal mass in a patient with a previous gynecological cancer. The long time follow up may reveal an adrenal tumour that actually is incidental but a suspected metastasis represents an important differential diagnosis. The size changes like doubling the maximum diameters may increase the index of suspicion and recommend surgery ${ }^{[5-7]}$. In literature the values vary from 4 
$\mathrm{cm}$ to $6 \mathrm{~cm}$ meaning that tumours with a larger diameters than these cut offs has an increased potential of been an adrenal cancer $^{[5-7]}$. Fortunately, in our case no carcinoma, neither a metastasis was found.

The second topic is related to the mildly abnormal secretor profile. The increased metanephrines (also when we repeated them they were normal) with normal normetanephrines is an atypical rare finding in some pheocromocytomas, adrenal cancers or paraganglioma but an adrenergic reaction caused by blood withdrawn is the real cause in most of times ${ }^{[8-10]}$.

The third point of view is the subclinical Cushing's syndrome. There are no clear thresholds in order to diagnose and recommend surgery so mainly it is an intra-individual decision. The presence of arterial hypertension with low-normal levels of ACTH and the dexamethasone suppression test results are virtually related to a subclinical adrenal Cushing's syndrome in this case ${ }^{[11,12]}$.

Bringing together all the mentioned points a clinician cannot appreciate for sure a malignant tumour in the adrenal but neither can say that there is not a cancer there so the surgery is the following step in the patient's management in order to obtain a precise pathological exam. The follow-up is necessary despite benign features since little is known about the real aetiology of this tumours type ${ }^{[13-16]}$.

\section{Conclusion}

The radiologic and endocrine anomalies associated to an adrenal mass in a patient with oncologic medical history may conclude to the idea of tumour removal for a certain diagnosis provided by pathological report.

\section{Acknowledgements}

We thank to the patient for giving her written consent to report her case and to the entire medical and surgical team involved in this case.

\section{References}

[1] Kerkhofs TM, Roumen RM, Demeyere TB, et al. Adrenal tumors with unexpected outcome: a review of the literature. Int J Endocrinol. 2015; 2015. http://dx.doi.org/10.1155/2015/710514

[2] Kastelan D, Kraljevic I, Dusek T, et al. The clinical course of patients with adrenal incidentaloma: is it time to reconsider the current recommendations? Eur J Endocrinol. 2015: EJE-15-0199.

[3] Tian L, Dong J, Mo YX, et al. Adrenal cortical adenoma with the maximal diameter greater than $5 \mathrm{~cm}$ : can they be differentiated from adrenalcortical carcinoma by CT? Int J Clin Exp Med. 2014; 7(10): 3136-43. PMid:25419344

[4] Nieman LK, Biller BM, Findling JW, et al. The diagnosis of Cushing's syndrome: an Endocrine Society Clinical Practice Guideline. J Clin Endocrinol Metab. 2008; 93(5): 1526-40. http://dx.doi.org/10.1210/jc.2008-0125

[5] Ballian N, Adler J, Sippel R, et al. Revisiting adrenal mass size as an indication of adrenalectomy. Journal of Surgical Research. 2009; 156; 16-20. http://dx.doi.org/10.1016/j.jss.2009.03.071

[6] Wang TS, Cheung K, Roman SA, et al. A cost-effectiveness analysis of adrenalectomy for nonfunctional adrenal incidentalomas: is there a size threshold for resection? Surgery. 2012; 152(6): 1125-32. http://dx.doi.org/10.1016/j.surg.2012.08.011

[7] Sturgeon C, Shen WT, Clark OH, et al. Risk assessment in 457 adrenal cortical carcinomas: how much does tumor size predict the likelihood of malignancy? J Am Coll Surg. 2006; 202(3): 423-30. PMid:16500246 http://dx.doi.org/10.1016/j.jamcollsurg.2005.11.005

[8] Birsen O, Akyuz M, Dural C, et al. A new risk stratification algorithm for the management of patients with adrenal incidentalomas. Surgery. 2014; 156(4): 959-65. http://dx.doi.org/10.1016/j.surg.2014.06.042

[9] Ctvrtlik F, Koranda P, Tichy T. Adrenal disease: a clinical update and overview of imaging. A review. Biomed Pap Med Fac Univ Palacky Olomouc Czech Repub. 2014; 158(1): 23-34. http://dx.doi.org/10.5507/bp.2014.010

[10] Beuschlein F. Adrenal incidentalomas: presentation and clinical work-up. Horm Res. 2007; 68(Suppl 5): 191-4. http://dx.doi.org/10.1159/000110623 
[11] Iacobone M, Citton M, Scarpa M, et al. Systematic review of surgical treatment of subclinical Cushing’s syndrome. Br J Surg. 2015; 102(4): 318-30. http://dx.doi.org/10.1002/bjs.9742

[12] Terzolo M, Bovio S, Pia A, et al. Management of adrenal incidentaloma. Best Pract Res Clin Endocrinol Metab. 2009; 23(2): 233-43. http://dx.doi.org/10.1016/j.beem.2009.04.001

[13] Kobus K, Hartl D, Ott CE, et al. Double NF1 inactivation affects adrenocortical function in NF1Prx1 mice and a human patient. PLoS One. 2015; 10(3): e0119030. http://dx.doi.org/10.1371/journal.pone.0119030

[14] Oudijk L, Neuhofer CM, Lichtenauer UD. Immunohistochemical expression of stem cell markers in pheochromocytomas/paragangliomas is associated with SDHx mutations. Eur J Endocrinol. 2015; 173(1): 43-52. PMid:25916394 http://dx.doi.org/10.1530/EJE-14-1164

[15] Juhlin CC, Goh G, Healy JM. Whole-exome sequencing characterizes the landscape of somatic mutations and copy number alterations in adrenocortical carcinoma. J Clin Endocrinol Metab. 2015; 100(3): E493-502. http://dx.doi.org/10.1210/jc.2014-3282

[16] Carney JA, Lyssikatos C, Lodish MB, et al. Germline PRKACA amplification leads to Cushing syndrome caused by 3 adrenocortical pathologic phenotypes. Hum Pathol. 2015; 46(1): 40-9. http://dx.doi.org/10.1016/j.humpath.2014.09.005 